Journal of Case Reports 2021;11(1):40-43

\title{
Amyand's Hernia: A Single Centre Experience
}

\author{
F Ftaieh, O Shams, MA Gok, MM Sadat, UA Khan \\ East Cheshire NHS Trust, Macclesfield District General Hospital, Macclesfield, United Kingdom.
}

\section{Corresponding Author:}

Dr MA Gok

Email: muhammed.gok@nhs.net

This is an Open Access article distributed under the terms of the Creative Commons Attribution License (creativecommons.org/ licenses/by/3.0).

Received : August 3, 2020

Accepted : December 19, 2020

Published : February 25, 2021

\begin{abstract}
Background: Amyand's hernia is an inguinal hernia which may contain caecum, bladder, ovary, fallopian tube, omentum, Meckel's diverticulum or vermiform appendix incarcerated within the hernia sac. Normal appendix lodged within an Amyand's hernia occurs in $1 \%$, whereas appendicitis within the hernia sac occurs in $0.1 \%$. Its presentation can be quite variable and pre-operative diagnosis is difficult. Case Report: This is a case study of two Amyand's hernias, initial presentation and subsequent emergency management. Both patients presented with appendicitis and a tender right inguinal hernia. Laparoscopic appendicectomy was carried out on the initial admission, and laparoscopic mesh repair of Amyand's hernia was deferred. Conclusion: Pre-operative clinical diagnosis is difficult but aided by ultrasound or computerised tomography scan. The presence of appendicitis requires appendicectomy. Repair of Amyand's hernia should be deferred, where laparoscopic mesh repair can be offered without the risk of mesh infection.
\end{abstract}

Keywords: Appendicitis, Appendix, Inguinal Hernia, Laparoscopy, Surgical Mesh, Urinary Bladder.

\section{Introduction}

Amyand's hernia occurs in $1 \%$ of inguinal hernias, in which a normal vermiform appendix is incarcerated within the hernia, whilst associated appendicitis occurs $0.1 \%$ of cases [1-3]. It is most commonly found in males, on the right, and can occur in any age. Amyand's hernia was first reported case in year 1736 (perforated appendicitis), but its pathophysiology and risk factors remain unclear [4]. It is believed to be secondary to a patent processus vaginalis or the presence of a fibrous band between the testes and hernia. Amyand's hernia usually presents as an incarcerated inguinal hernia, but its presentation can be quite variable. Inguinal hernias are typically diagnosed clinically or with ultrasound. Computed tomography scan (CT) is the most commonly used imaging modality for evaluation of complex abdominal hernias.
Appendicitis arises from luminal obstruction (i.e. appendocolith), causing bacterial overgrowth, increased pressure and localized ischaemia, resulting in appendicitis, gangrenous perforation, thus leading to localized abscess or peritonitis. Appendicitis can also occur as a result of strangulation of the appendix within the Amyand's hernia. Appendicitis present with right iliac pain, vomiting, fever, loss of appetite and raised inflammatory markers [(white cell count (WCC), C-reactive protein (CRP)]. Appendicectomy is the treatment of choice and this is increasingly done as a laparoscopic procedure [5].

The aim of the study is to illustrate two cases where patients experienced appendicitis within an Amyand's hernia. These two cases illustrate the management of appendicitis prior to repair of the Amyand's hernia. 


\section{Case Reports}

\section{Case 1}

A 83 years old female with past history of right inguinal hernia, abdominal hysterectomy, hypercholesterolemia, primary hyperparathyroidism, hypertension, hypercalcemia and osteopenia, presented to the A \& E (accident and emergency) department with acute right groin pain, abdominal distension and rigors for 3 days. She was having tender right iliac fossa and right inguinal hernial canal. She had a temperature $\left(38^{\circ} \mathrm{C}\right)$, tachycardia (heart rate 113 beat per minute) with pain score 8/10 (Numerical Pain Rating Scale), CRP $120 \mathrm{mg} / \mathrm{L}$ and white cell count 10.6 x $10^{9} / \mathrm{L}$. Arterial blood gases $(\mathrm{ABG})$ demonstrated respiratory alkalosis on room air $\left(\mathrm{pH} \mathrm{7.47,} \mathrm{pCO}_{2}\right.$ $4.2 \mathrm{kPa}, \mathrm{HCO}_{3} 23.3 \mathrm{mmol} / \mathrm{L}$ ) and lactate of $2 \mathrm{mmol} / \mathrm{L}$. She was commenced on intravenous fluids and kept nil per mouth, and catheterized. Inpatient $\mathrm{CT}$ scan demonstrated acute appendicitis herniating into the inguinal hernia [Fig.1]. She was commenced on intravenous antibiotics. She subsequently underwent laparoscopic appendectomy on the NCEPOD (national confidential enquiry into patient outcomes \& deaths) list, where an acutely inflamed gangrenous appendix was found within the right inguinal hernia [Fig.2]. Post-operative recovery was generally uneventful and patient was discharged with oral antibiotics for 5 days. Histopathology demonstrated transmural neutrophilic inflammation of the appendix extending in to the peri-appendicular fat with perforation and purulent serositis [Fig.3]. Patient subsequently underwent laparoscopic totally extra-peritoneal hernia (TEP) repair 6 months later.

\section{Case 2}

60 years old male with benign hypertrophy of prostate and glaucoma presented in A\&E with acute abdominal pain (central abdominal with migration to right inguinal fossa) for 1 day.
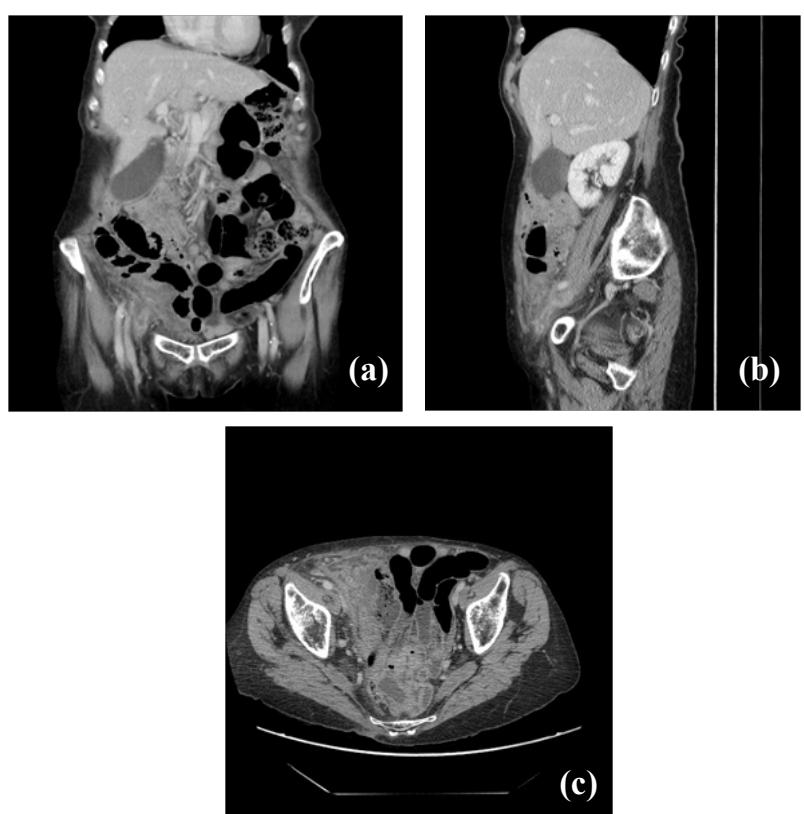

Fig.1: Case 1 CT scan (a) coronal view; (b) sagittal view; (c) axial view. Inflamed appendix in right inguinal canal.

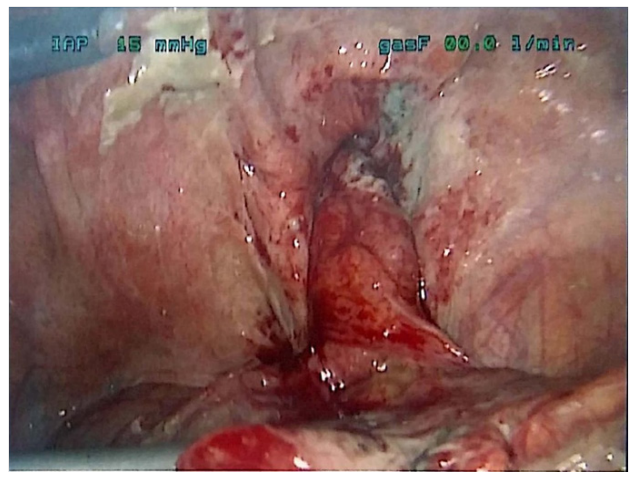

Fig.2: Case 1 inflamed gangrenous appendix in the right inguinal canal (laparoscopic view).

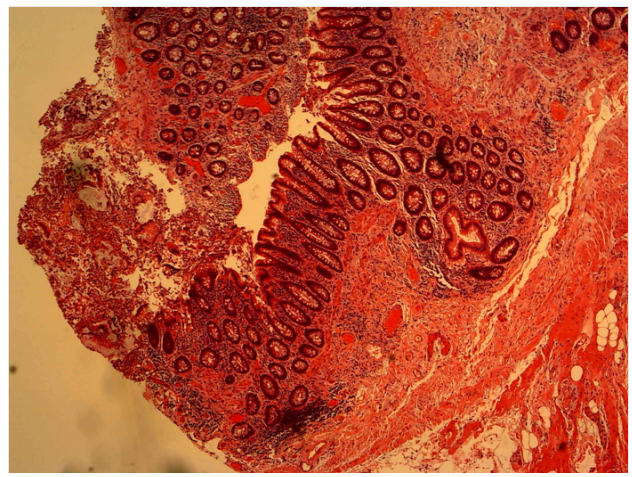

Fig.3: Case 1, Histopathology of appendix extending in to the peri-appendicular fat with perforation and purulent serositis. 
Clinically he had a painful right groin swelling with onset of abdominal pain, without fever. He had generalised abdominal tenderness which centralised over the Mcburney's point. On his right inguinal area there was $2 \times 4 \mathrm{~cm}$ swelling, no cough impulse, pulsation, tenderness or erythema. Bowel sounds were heard. Serological tests showed raised inflammatory markers (WCC $13.9 \times 10^{9}$, CRP $77 \mathrm{mg} / \mathrm{L}$ ). A subsequent CT scan demonstrated acute appendicitis in a right inguinal hernia (Amyand's hernia) [Fig.4]. He was commenced on intravenous antibiotics. $\mathrm{He}$ underwent laparoscopic appendectomy on the NCEPOD list. Omental wrapping of inflamed appendix was found in the right inguinal canal [Fig.5]. The tip was adhered to the hernia sac and had to be freed by blunt dissection associated with reducing the hernia with external pressure. The appendix was dissected out of the hernia successfully via blunt dissection and some hydro-dissection with external pressure on the hernia. Post-operative period was uneventful and patient was subsequently discharged with oral antibiotics with review in out-patient clinic for elective laparoscopic inguinal hernia repair. Histopathology of the appendix showed mucosal ulceration with transmural acute necrotising inflammation and serositis [Fig.6].

\section{Discussion}

Amyand's hernia is most frequently reported in men, on the right side, exceptions occur in situs inversus, intestinal mal-rotation, a very mobile caecum or a large appendix [6]. Amyand's hernia may contain cecum, bladder, ovary, fallopian tube, omentum or a Meckel's diverticulum. Amyand's hernia usually presents as strangulated or incarcerated hernia with coincidental finding of appendix in the hernia. Appendicitis can result from either obstruction or direct trauma over the hernia, resulting in a reduced vascular flow, ischemia and infection.

Pre-operative clinical diagnosis is difficult, but can be aided by trans-abdominal ultrasound or
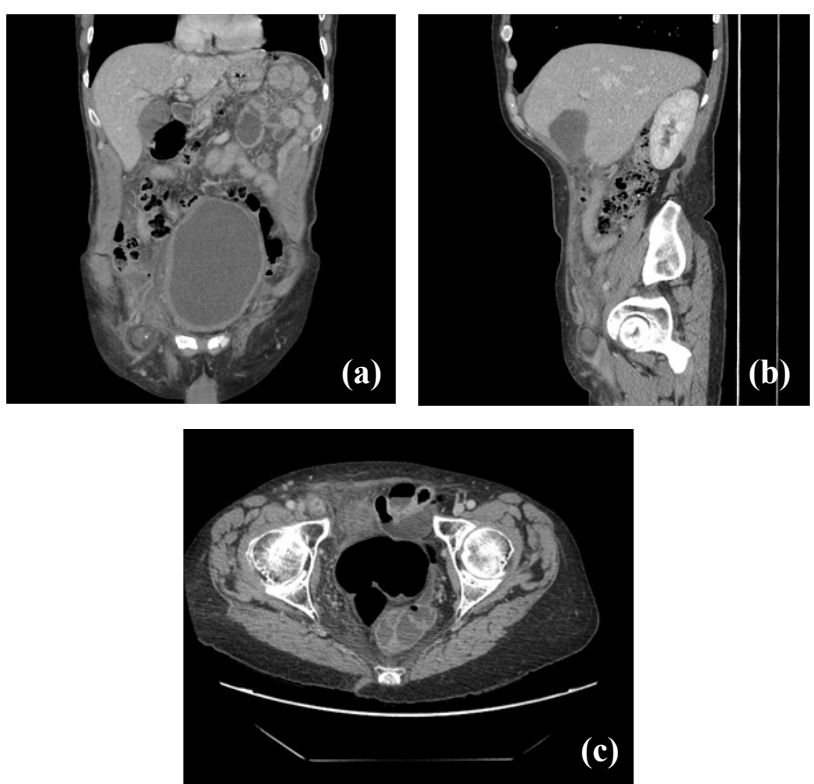

Fig.4: Case 2 CT scan (a) coronal view; (b) sagittal view; (c) axial view. Inflamed appendix in right inguinal canal.

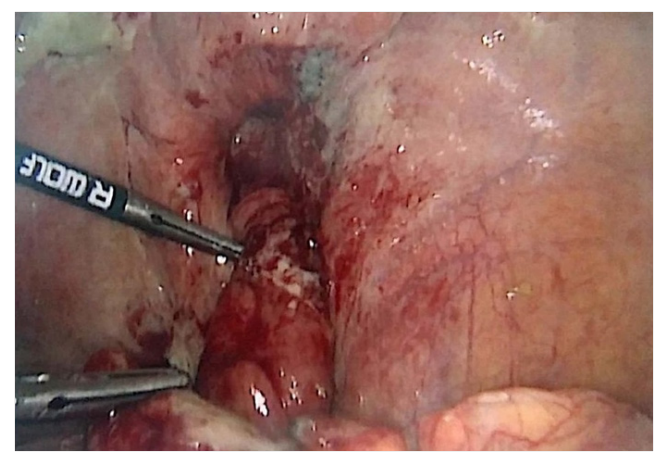

Fig.5: Case 2, Omental wrapping of inflamed appendix was found in the right inguinal canal (laparoscopic view).

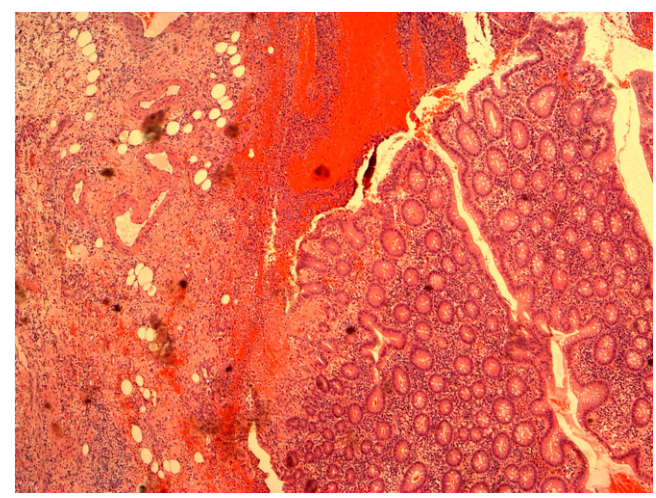

Fig.6: Case 2, Histopathology of the appendix showed mucosal ulceration with transmural acute necrotising inflammation and serositis. 
Table 1: Losanoff and Basson classification of Amyand's hernia and management.

\begin{tabular}{|l|l|l|}
\hline Classification & Description & Surgical management \\
\hline Type 1 & Normal appendix within an inguinal canal. & $\begin{array}{l}\text { Hernia reduction, mesh repair, appendicectomy only } \\
\text { in young patients. }\end{array}$ \\
\hline Type 2 & $\begin{array}{l}\text { Acute appendicitis within an inguinal hernia, no } \\
\text { abdominal sepsis. }\end{array}$ & $\begin{array}{l}\text { Appendicectomy through hernia, primary repair of } \\
\text { hernia, no mesh. }\end{array}$ \\
\hline Type 3 & $\begin{array}{l}\text { Acute appendicitis within an inguinal hernia, } \\
\text { abdominal wall, or peritoneal sepsis. }\end{array}$ & $\begin{array}{l}\text { Laparotomy, appendicectomy, primary repair of } \\
\text { hernia, no mesh. }\end{array}$ \\
\hline Type 4 & $\begin{array}{l}\text { Acute appendicitis within an inguinal hernia, related } \\
\text { or unrelated abdominal pathology. }\end{array}$ & $\begin{array}{l}\text { Manage as types 1 to 3 hernia, investigate or treat } \\
\text { second pathology as appropriate. }\end{array}$ \\
\hline
\end{tabular}

computed tomography CT scan [7-9]. Diagnostic laparoscopy can also demonstrate a Amyand hernia with a tubular blind-ended structure originating from the cecum wall and extending to the hernia sac. There is no standardized treatment for Amyand's hernias. Losanoff and Basson proposed an Amyand hernia classification system in 2007 with guidelines for surgical management (Table 1) [10,11]. Management should be individualized according to each case in respect to patient co-morbidities.

\section{Conclusion}

These two cases demonstrated Amyand's hernia, presenting with typical features of appendicitis. At diagnostic laparoscopy, the inflamed appendix was found in the inguinal canal.These two patients underwent laparoscopic appendicectomy, but didn't have their hernias repaired at the time of the operation as there was too much inflammation.

Contributors: FF: Manuscript writing, patient management; OS, MAG: manuscript revision and patient management; MMS, UAK: critical inputs into the manuscript and patient management. MAG will act as study guarantor. All authors approved the final version of the manuscript and are responsible for all aspects of the study.

Funding: None; Competing interests: None stated.

\section{References}

1. Baldassarre E, Centonze A, Mazzei A, Rubino R. Amyand's hernia in premature twins. Hernia. 2009;13(2):229-230.
2. Sharma H, Gupta A, Shekhawat N, Memon B, Memon M. Amyand's hernia: a report of 18 consecutive patients over a 15-year period. Hernia. 2007;11(1):31-35.

3. Burgess P, Brockmeyer J, Johnson E. Amyand hernia repaired with Bio-A: a case report and review. J Surg Educ. 2011;68(1):62-66.

4. Amyand C. Of an inguinal rupture, with a pin in the appendix coeci, incrusted with stone; and some observations on wounds in the guts. Philosophical Transactions of the Royal Society of London. 1735;39(8):329-342.

5. Jaschinski T, Mosch C, Eikermann M, Neugebauer E, Sauerland S. Laparoscopic versus open surgery for suspected appendicitis. Cochrane Database Syst Rev. 2018;11(11): CD001546.

6. Unver M, Ozturk S, Karaman K, Turgut E. Left sided Amyand's hernia. World J Gastrointest Surg. 2013;5(10):285-286.

7. Maekawa T. Amyand's hernia diagnosed by computed tomography. Intern Med. 2017;56(19):2679-2680.

8. Guler I, Alkan E, Nayman A, Tolu I. Amyand's hernia: Ultrasonography findings. J Emerg Med. 2016;50(1):e1517.

9. Constantine S. Computed tomography appearances of Amyand hernia. J Comput Assist Tomogr. 2009;33(3):359-362.

10. Losanoff J, Basson M. Amyand hernia: what lies beneath-a proposed classification scheme to determine management. Am Surg. 2007;73(12):1288-1290.

11. Losanoff J, Basson M. Amyand hernia: a classification to improve management. Hernia. 2008;12(3):325-326. 